\title{
New organic binary solids with phenolic coformers for NLO applications
}

\author{
Sergiu Draguta, ${ }^{1}$ Marina S. Fonari, ${ }^{1,2}$ Evgenia Leonova, ${ }^{1}$ Tatiana V. Timofeeva ${ }^{1,3 *}$
}

\author{
${ }^{\text {I}}$ Department of Biology and Chemistry, New Mexico Highlands University, Las Vegas, NM, 87701, USA \\ ${ }^{2}$ Institute of Applied Physics Academy of Sciences of Moldova, Academy str., 5 MD2028, Chisinau, \\ Moldova \\ ${ }^{3}$ ITMO University, St. Petersburg 197101, Russia
}

\begin{abstract}
Five binary adducts between N,N-dimethyl-4-[(E)-2-(pyridin-4-yl)ethenyl]aniline) 1, N,N-diethyl-4-[(E)-2-(pyridin-4-yl)ethenyl]aniline) 2, N,N-dimethyl-4-[(E)-pyridin-3-yldiazenyl]aniline 3, and coformers that include 4-nitrophenol I, 4-nitrobenzoic acid II, benzene-1,3-diol III, and 2,4dinitrophenol IV were synthesized to follow the factors influencing the formation of polar crystals. New solids were characterized by melting points and absorption spectra, while their structures were proven by single crystal X-ray diffraction. Adducts differ by the components' ratio and position of the acidic hydrogen atom, thus giving examples of four new cocrystals and one salt. The single crystal X-ray analysis revealed the acentric packing for two compounds, $\mathbf{1} \cdot(\mathbf{I})$ and $3(\mathbf{3})^{\circ}$ (III) that crystallize in the $P c a 2_{1}$ and $P 1$ space groups. The melting point data and the cut-off wavelength from absorption spectra show that these materials are stable till relatively high temperatures and transparent in a wide range of spectrum.
\end{abstract}

Keywords: Chromophore, Cocrystal, Non-linear optics, X-ray study, Spectroscopy

\section{Introduction}

The search for new materials for non-linear optics (NLO) remains in focus of crystal engineers for decades [1-4]. Organic compounds with extended conjugated system between the donor and acceptor groups are good candidates for NLO due to their high molecular hyperpolarizability, fast electronic response and thermal stability [2]. In order to be NLO active, noncentrosymmetric molecular packing is required. The formation of the acentric hydrogen-bonded systems was suggested by M. Etter as the prerequisite for the acentricity in organic solids and was confirmed by the nitroaniline and ureacontaining crystals [5-8]. It was also proven that organic salts demonstrate the higher values of molecular hyperpolarizability compared to cocrystals that comprise the neutral components [9]. The discovery of 4(4-(dimethylamino)styryl)-1-methylpyridinium-4-methylbenzenesulfonate (DAST) [10-12] with strong 
Columbic interactions between the charged dipole entities has opened a modern era of NLO materials, being generated by the slight modifications of the DAST components, 4-(4-(dimethylamino)styryl)-1methylpyridinium-4 cation and methylbenzenesulfonate anion [13-18].

We have recently reported the acentric binary crystalline organic solids composed of different aminopyridines and 4-nitrophenol [19]. The combination of these components resulted in strong hydrogen bonding and the proton transfer that increases the molecular hyperpolarizability [19-21]. In the 4nitrophenol molecule the phenolic group exhibits amphoteric properties acting as hydrogen-bond donor through the hydroxyl H-atom, and electron-donor as well through the oxygen atom lone pair, while the nitro-group is displaying the electron- and hydrogen-bond acceptor properties. In the present work we combine 4-nitrophenol I, and its analogues and derivatives, 4-nitrobenzoic acid II, 1,3-benzene-diol III, and 2,4-dinitrobenzene diol IV with the chromophores that differ from the previously reported by us amino- and N-methylaminosubstituted pyridines [19, 22], by possessing longer conjugation system. These base compounds include N,N-dimethyl-4-[(E)-2-(pyridin-4-yl)ethenyl]aniline) 1, N,N-diethyl-4[(E)-2-(pyridin-4-yl)ethenyl]aniline) 2, and N,N-dimethyl-4-[(E)-pyridin-3-yldiazenyl]aniline $\mathbf{3}$, and together with the coformers used in this study are shown in Scheme 1.

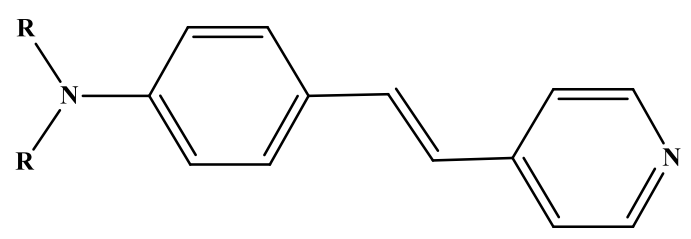

$\mathbf{R}=\mathbf{M e} 1$

$\mathbf{R}=\mathbf{E t} \quad 2$

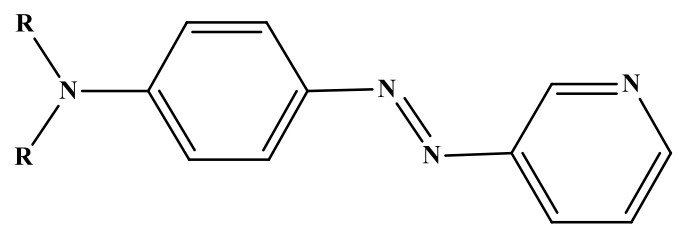

$\mathbf{R}=$ Me 3

$\mathbf{R}=\mathbf{E t} \quad 4$
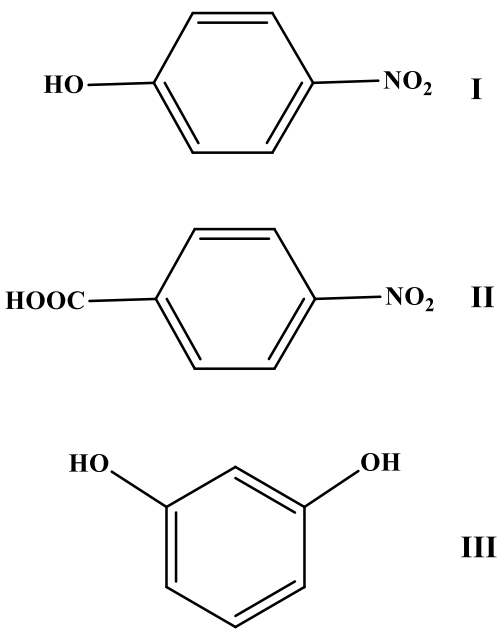

III

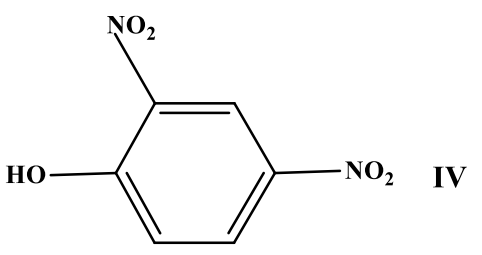

Scheme 1. Schematic notation for compounds used in this study.

Contrary to the reported series of DAST compounds, the non-substituted pyridine nitrogen atom in all these bases provides an opportunity for the hydrogen bonding and donor-acceptor charge transfer. The choice of coformers is explained on one hand by the presence in all of them the strong H-donor in the 
form of hydroxy group capable to generate the robust $\mathrm{OH}^{\cdots \cdots} \mathrm{N}$ (pyridine) heterosynthon [23], and on the other hand by the fact that the crystals of the pure forms of 1,3-benzene-diol III [24], 2,4-dinitrophenol IV [25-27], and several of their adducts are acentric solids [28,29] studied as NLO materials [30]. By changing the position of the pyridine nitrogen atom, N-substituents, and bridge in chromophores on one hand, and the coformers on the other hand, we tried to understand the outcome of these changes along with influence of functional groups on the acentric crystal packing. In this paper we also present the newly synthesized N,N-dimethyl-4-[(E)-pyridin-3-yldiazenyl]aniline 3 [31], and its acentric adduct with benzene-1,3-diol III. According to the early data, the azo chromophores similar to $\mathbf{3}$ and $\mathbf{4}$ (recently reported by us) [32] can display additional useful properties such as enhanced thermal, oxidative, and photochemical stability. In addition, the [(aminophenyl)azo]-pyridinium moieties should be resistant to the degradative $[2+2]$ cycloaddition pathways $[23,33]$ that present potential complications in some stilbazolium systems resulting in the reduced NLO activity [34]. Furthermore, the altered position of pyridine nitrogen atom in $\mathbf{3}$ and $\mathbf{4}$ compared with $\mathbf{1}$ and $\mathbf{2}$ might impose additional asymmetry in the generated hydrogen-bonding patterns assisting acentric crystal packing.

\section{Results and Discussion}

\subsection{General}

The combination of starting materials (Scheme 1) has resulted in five binary solids, $\mathbf{1} \cdot(\mathbf{I}), \mathbf{2} \cdot(\mathbf{I I})$, $2(\mathbf{2}) \cdot($ III $), 3(\mathbf{3}) \cdot($ III) and $\mathbf{3}(\mathbf{I V})$, including two polar crystals, $\mathbf{1} \cdot(\mathbf{I})$ and $3(\mathbf{3}) \cdot($ III) that crystallize in the acentric space groups $P c a 2_{1}$ and $P 1$, respectively. No adducts with 4 were obtained so far. The main crystallographic data for new compounds are summarized in Table 1, the hydrogen bond parameters are given in Table 2. Except for $\mathbf{1}$ and $\mathbf{1}(\mathbf{I})$, that are orange, all other starting chromophores and the final adducts are red solids (Fig. 1). The plot in Fig. 2 combines the melting points for the starting materials and the final products. It demonstrates thermal stability of adducts since their melting points are ranging from $185(2)$ to $245(2){ }^{\circ} \mathrm{C}$, approaching corresponding values for the initial bases.
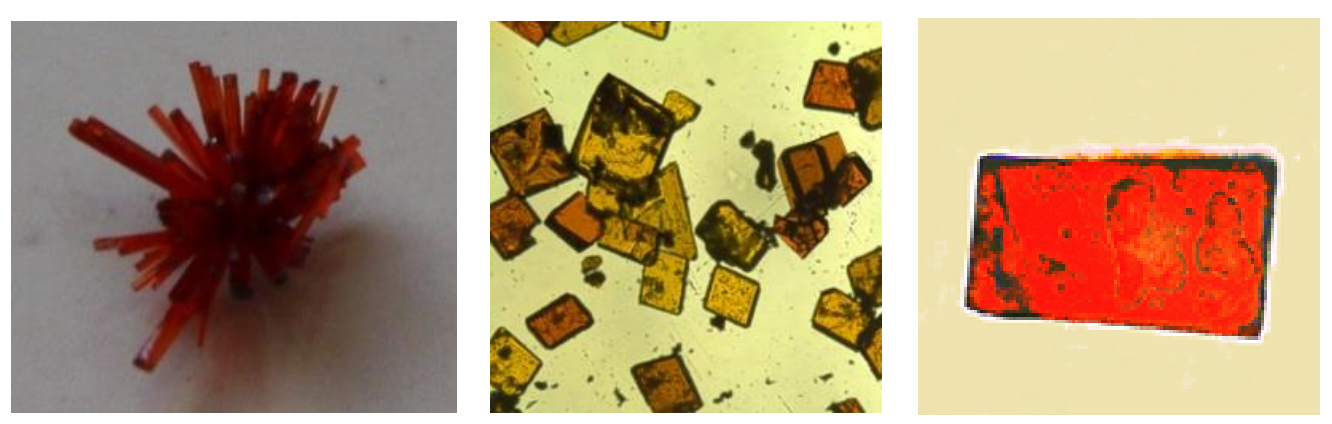

Fig. 1. Single crystals photos for $\mathbf{3}, \mathbf{4}$, and $\mathbf{1}(\mathbf{I})$. 


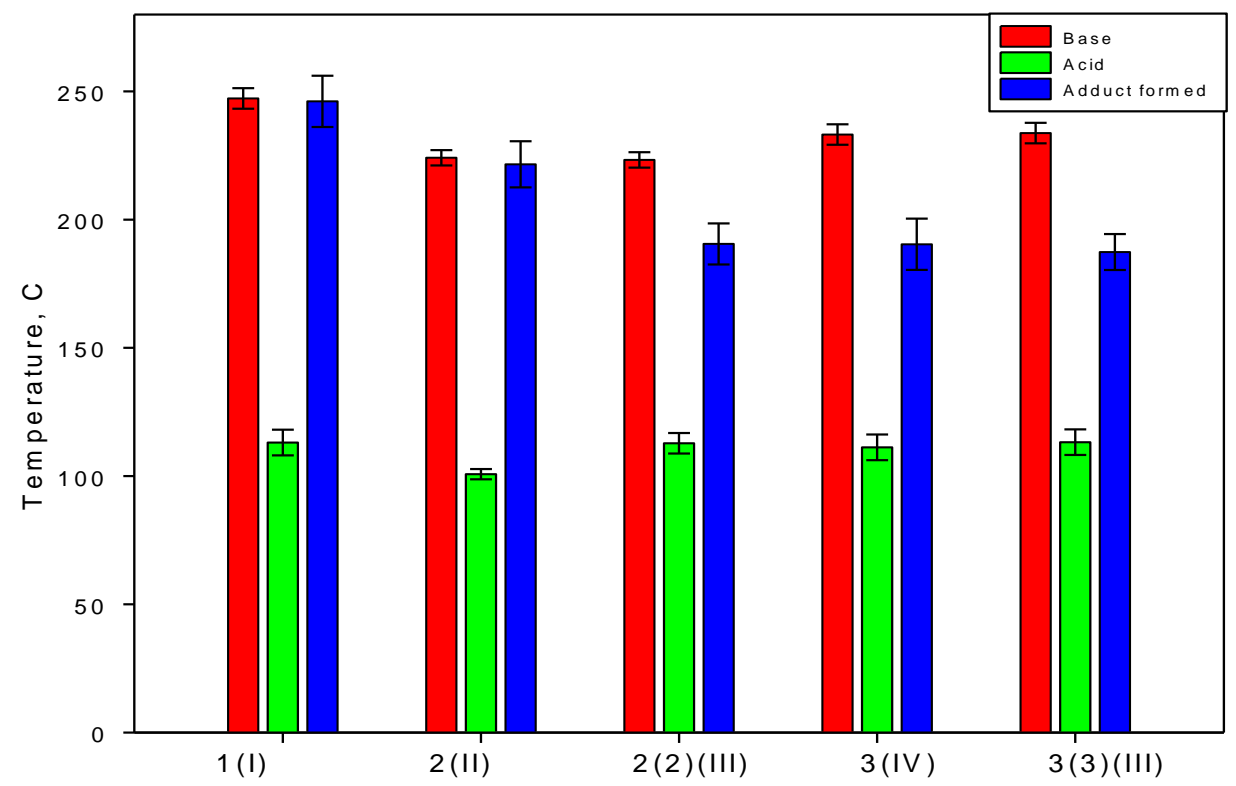

Fig. 2. Diagram showing the melting points for the initial coformers and the final adducts.

\subsection{Crystal structures}

N,N-dimethyl-4-[(E)-pyridin-3-yldiazenyl]aniline 3 (Fig. 3a) crystallizes in the centrosymmetric monoclinic space group $P 2_{1} / c$ contrary to the recently reported by us N,N-diethyl-4-[(E)-pyridin-3yldiazenyl]aniline 4 that crystallizes in the acentric $P 2_{1} 2_{1} 2_{1}$ space group [32]. Similar to $\mathbf{4}$, molecule 3 adopts a trans-conformation with respect to the diazo $\mathrm{N}=\mathrm{N}$ bond. The twisted shape of the molecule is described by the dihedral angle between the benzene and pyridine rings of $21.56(5)^{\circ}$ [8.03 (5) ${ }^{\circ}$ in 4 ]. The T-shape arrangement of the molecules in crystal is reinforced by the weak $\mathrm{C}(1) \mathrm{H}^{\cdots \cdots} \mathrm{N}(2)$ hydrogen bond $\left(2.56,3.343(2) \AA, 142^{\circ}\right)$ with participation of the bridging $\mathrm{N}$-atom that supports the stair-case chains. The chains are running along the crystallographic $c$ axis. The dihedral angle between the neighboring molecules in chain is $89.83(1)^{\circ}$. The antiparallel packing of these chains provides the stacks of the molecules with the alternating interplanar separations of 3.53 and $3.64 \AA$ (Fig. 3b). Our CSD search [35] revealed no similar $\mathrm{CH}^{\cdots} \mathrm{N}$ interactions with participation of the bridging nitrogen atoms in the relative structures $[36,37]$. 


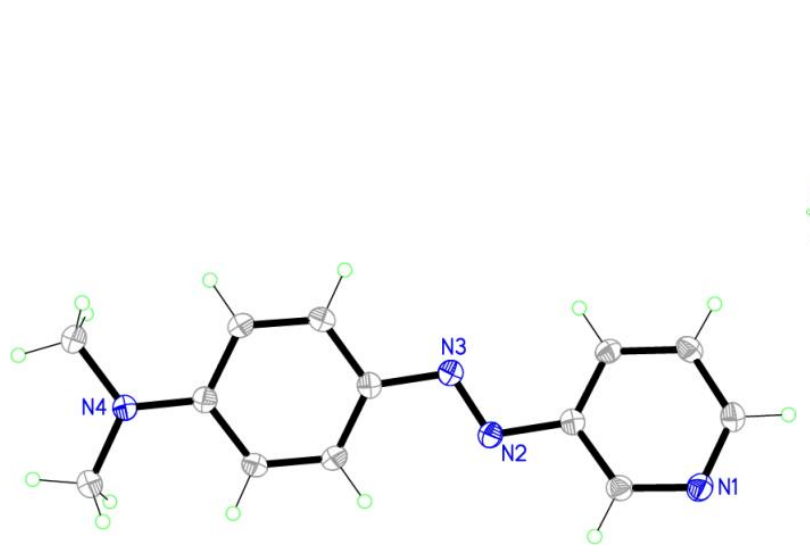

(a)

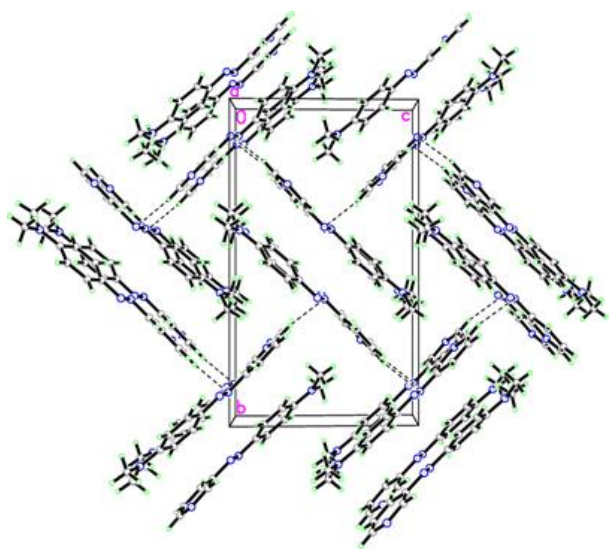

(b)

Fig. 3. (a) View of molecule 3 with partial numbering scheme. Thermal ellipsoids are drawn with the $50 \%$ probability level. (b) Fragment of crystal packing in $\mathbf{3}$. Hydrogen bonds are shown by dashed lines.

Analysis of the difference Fourier maps at the latest stages of the refinements for the adducts described below allowed to unambiguously locate the positions of functional hydrogen atoms, and to conclude that four adducts, $\mathbf{1}^{\cdot}(\mathbf{I}), \mathbf{2}(\mathbf{I I}), 2(\mathbf{2})^{\circ}$ (III), $3(\mathbf{3})^{\circ}(\mathbf{I I I})$ are cocrystals with no proton transfer, and only one, 3 (IV) represents an organic salt, since the proton transfer occurs from the phenoxy group to the pyridine $\mathrm{N}$-atom. Two of these adducts, $\mathbf{1}(\mathbf{I})$ and $3(\mathbf{3})^{\cdot}(\mathbf{I I I})$ crystallize in the acentric space groups, $P c a 2_{1}$ and $P 1$, respectively, and three, $2 \cdot(\mathbf{I I}), 2(\mathbf{2}) \cdot(\mathbf{I I I})$ and $\mathbf{3}$ (IV) crystallize in the centrosymmetric space groups. The stoichiometric ratios are primarily dictated by the number of H-donor (hydroxy) groups in the acidic molecules, being the expected $1: 1$ in $\mathbf{1}(\mathbf{I}), \mathbf{2}(\mathbf{I I})$, and $\mathbf{3}(\mathbf{I V}), 2: 1$ in $2(\mathbf{2}) \cdot(\mathbf{I I I})$, and an unusual $3: 1$ in $3(\mathbf{3})^{\circ}(\mathbf{I I I})$.

Adduct 1-(I) crystallizes in the non-centrosymmetric orthorhombic Pca2 $2_{1}$ space group. In the binary formula unit neutral molecules are held together via single $\mathrm{OH}^{\cdots \cdots} \mathrm{N}$ hydrogen bond, $\mathrm{O}^{\cdots \cdots} \mathrm{N} 2.681(3)$ $\AA$ (Fig. 4a, Table 2) that provides an insignificant twist within the adduct described by the dihedral angle of $14.9(5)^{\circ}$ between the mean planes of the skeletons of the molecules. The hydrogen bond that acts in a head-to-tail mode affords a linear and one-way arrangement of the effective axes of both dipole moments of the molecules. The adducts related by the two-fold screw axis form the double layers terminated by the 4-nitrophenol molecules, with the layer thickness of $1 / 2 a=21.486 \AA$ (Fig. 4b), and the herringbone arrangement of the chromophore molecules within the layer that is described by the dihedral angle of 59.2(4) ${ }^{\circ}$ between the skeletons of these molecules (Fig. 4c). 


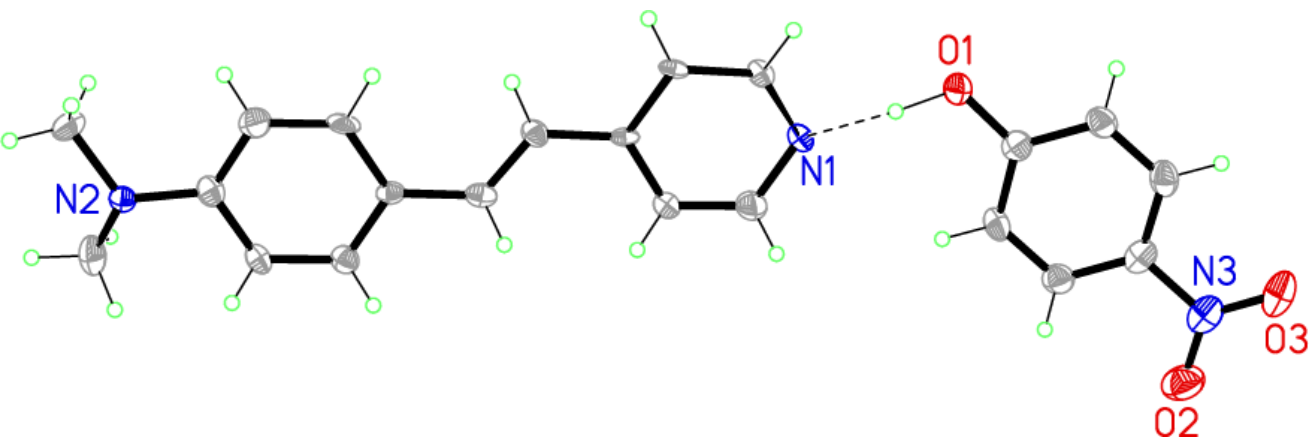

(a)

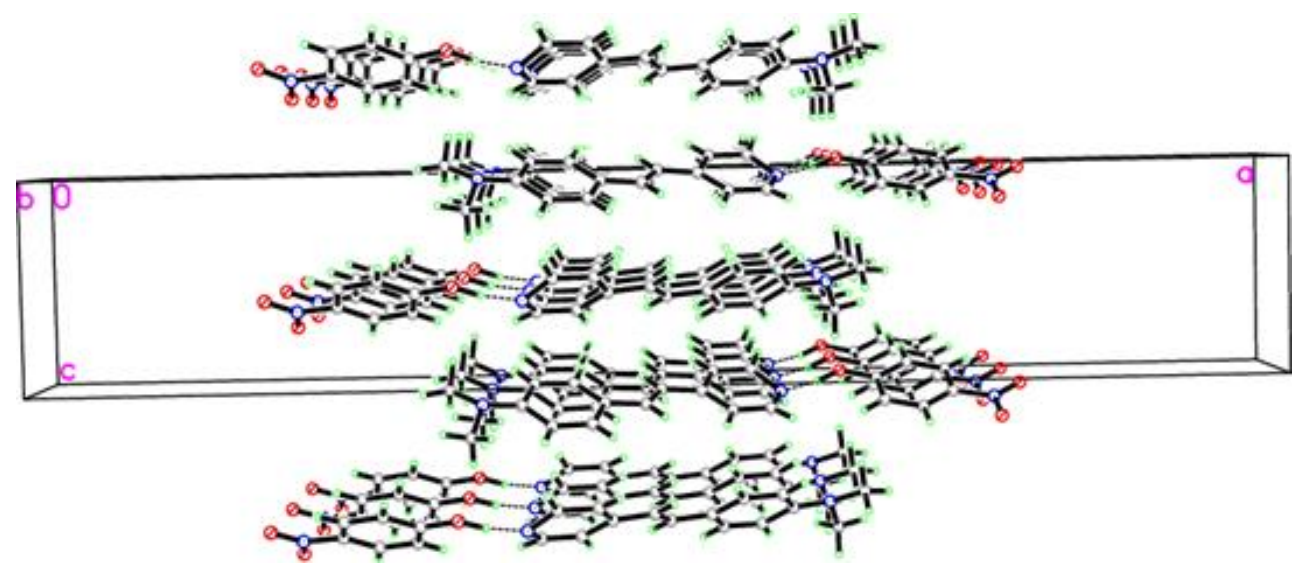

(b)

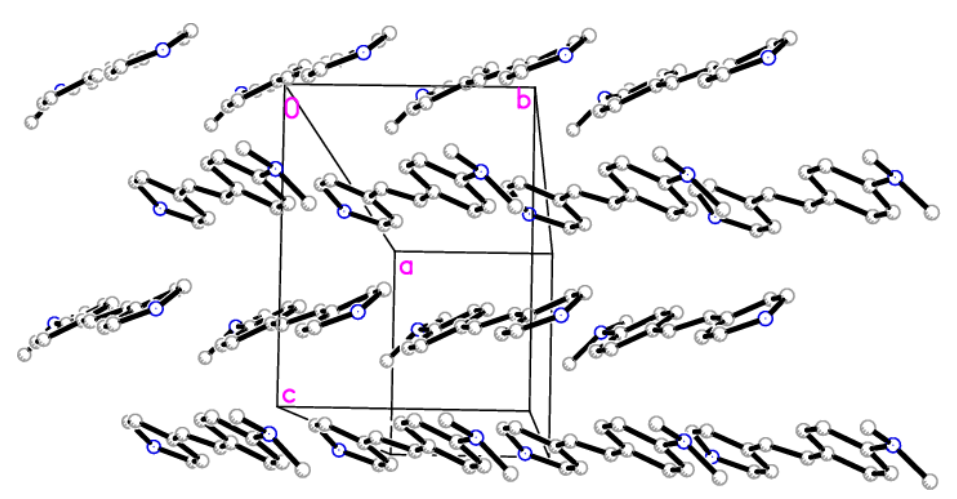

(c)

Fig. 4. (a) View of the formula unit in $\mathbf{1}(\mathbf{I})$. Thermal ellipsoids are drawn with the $50 \%$ probability level. Hydrogen bond is shown by dashed line. (b) Side view of the layer running parallel to the $b c$ plane. (c) Fragment of molecular packing demonstrating chromophore area. H-atoms are omitted for clarity.

Three adducts crystallize in the centrosymmetric space groups, $\mathbf{2}$ (II) and $2(\mathbf{2}) \cdot($ III $)-$ in the triclinic space group $P-1$, and $\mathbf{3}(\mathbf{I V})$ - in the monoclinic space group $P 2_{1} / n$, and thus they are not interesting materials for NLO applications. As it has been already mentioned, the proton transfer with the 
salt formation was registered only in $\mathbf{3}(\mathbf{I V})$, that is most probably promoted by the two nitro-groups in favorable positions increasing the acidity of phenoxy-group. The $1: 1$ formula units for $2 \cdot($ II) and 3 (IV) are shown in Fig. 4a,b, whose planarities are favored by the $R_{2}^{2}(7)$ and $R_{2}{ }^{2}(9)$ heteromolecular synthons, respectively, generated in each of these solids via combination of strong $\mathrm{NH}^{\cdots} \mathrm{O}$ hydrogen bond with the $\mathrm{CH}^{\cdots} \mathrm{O}$ hydrogen bond with the $\mathrm{CH}$-group neighboring to the pyridine/pyridinium nitrogen (Table 2). The stilbazole-based adduct $\mathbf{2} \cdot(\mathbf{I I})$ has a linear shape, while the diazolium-based adduct $\mathbf{3}(\mathbf{I V})$ has an angular shape caused by the different position of the pyridine nitrogen atom. As we have already mentioned recently [22] the planarity enhancement in the systems facilitates antiparallel centrosymmetric crystal packing that is rational for $\mathbf{2}(\mathbf{I I})$ where adducts are packed into centrosymmetric aggregates associated by the weak $\mathrm{CH}^{\cdots} \mathrm{O}$ hydrogen bonds between methyl and nitro groups $[\mathrm{C}(22)-\mathrm{H}(22 \mathrm{a}) \cdots \mathrm{O}(4)(2-x, 1-y, 2-z)$ 2.51, 3.389(3) $\AA, 152^{\circ}$ ], with the perfect overlap of the binary entities (Fig. 5c). Adducts 3(IV) stack in columns along the crystallographic $b$ axis with the interplanar separations of 3.203 and $3.286 \AA$ between the uniform entities (chromophore and 2,4-dinitrophenol) in stacks (Fig. 5d).

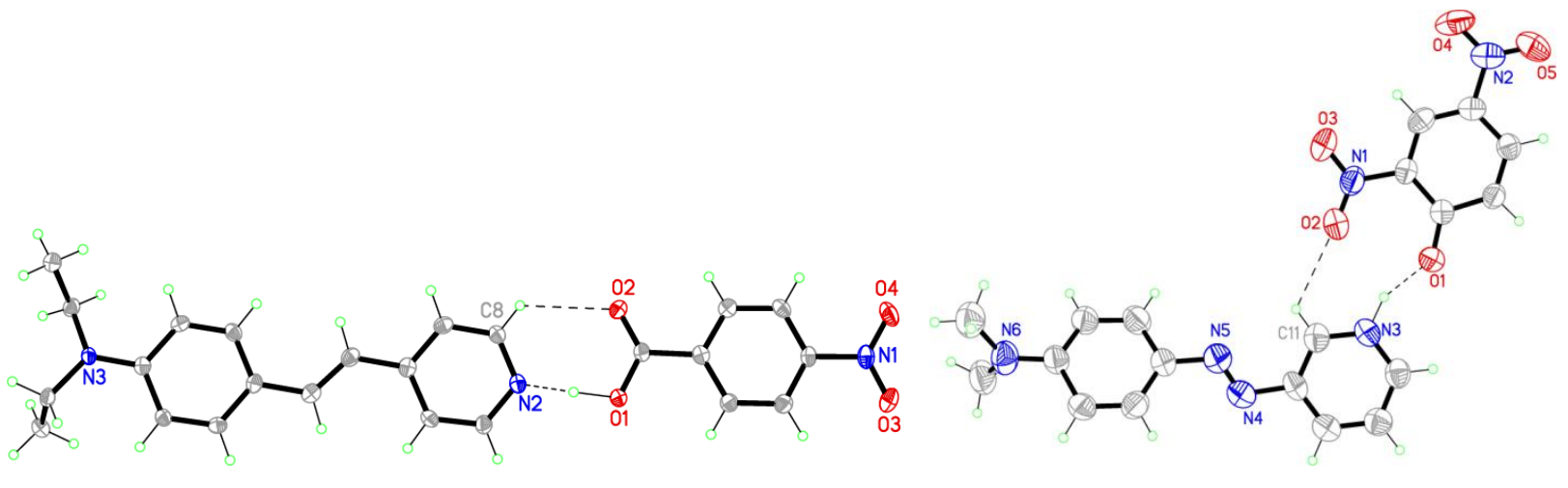

(a)

(b)

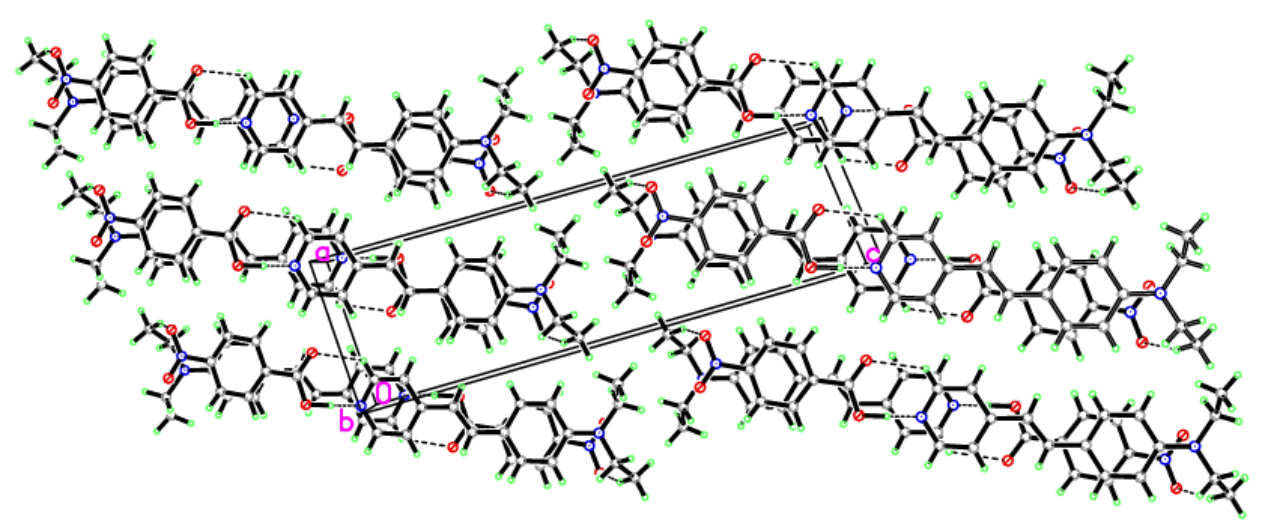

(c) 


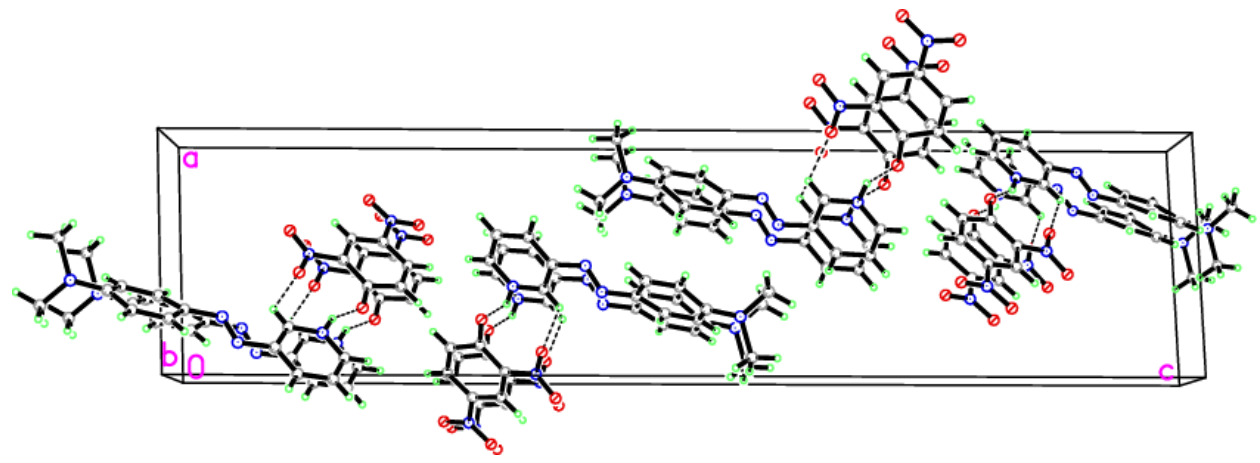

(d)

Fig. 5. (a) View of the formula unit in $\mathbf{2}$ (II). (b) View of the formula unit $\mathbf{3}(\mathbf{I V})$. Thermal ellipsoids are drawn with the $50 \%$ probability level. Hydrogen bonds are shown by dashed lines. (c) Fragment of crystal packing in $\mathbf{2}$ (II). The centrosymmetric packing is assisted by the weak $\mathrm{CH}^{\cdots}{ }^{\cdots} \mathrm{O}$ hydrogen bonds between methyl and nitro groups $\left(2.51,3.389 \AA, 152^{\circ}\right)$ that combine two binary complexes into centrosymmetric adducts. (d) Centrosymmetric crystal packing in $3 \cdot(\mathbf{I V})$ with the stacks of the identical molecules.

In the cocrystal $2(2) \cdot($ III) with the $2: 1$ molar ratio the asymmetric unit comprises two crystallographically different chromophore molecules 2 in general positions, and two halves of benzene-1,3-diol molecules III that occupy two different inversion centers in the centrosymmetric $P-1$ space group, providing the disordering of each hydroxy group over two positions and excluding the acentric packing. Each chromophore and resorcinol molecules are associated into two pairs of similar trimers (Fig. 6a) via a couple of $\mathrm{OH}^{\cdots} \mathrm{N}$ hydrogen bonds, $\mathrm{O}^{\cdots} \mathrm{N}$ distances being in the range 2.735(5) - 2.798(5) $\AA$ (Table 2). The linear adducts differ by the degrees of planarity, as the dihedral angles between the non- $\mathrm{H}$ skeletons of the components (excluding ethyl groups in 2) of 13.56(7) ${ }^{\circ}$ and 33.56(13) ${ }^{\circ}$ in two of them indicate. The chromophores pack in an edge-to-face mode with the interplanar angle of $71.06(7){ }^{\circ}$ between their aromatic backbones (Fig. 6b).

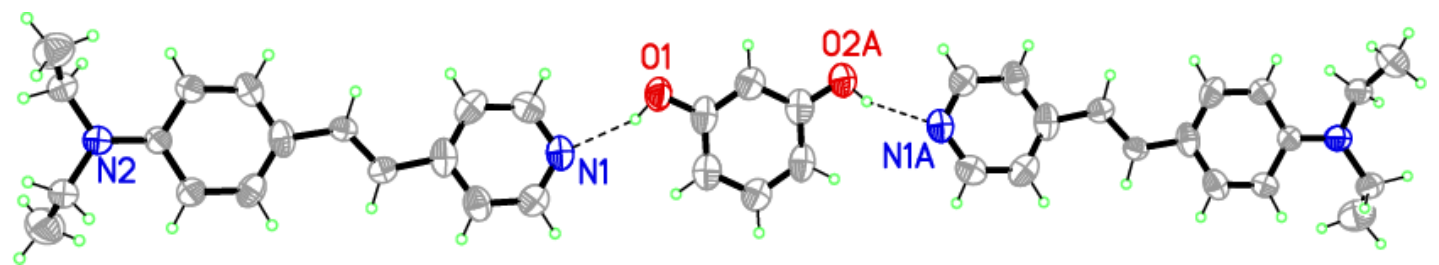

(a) 


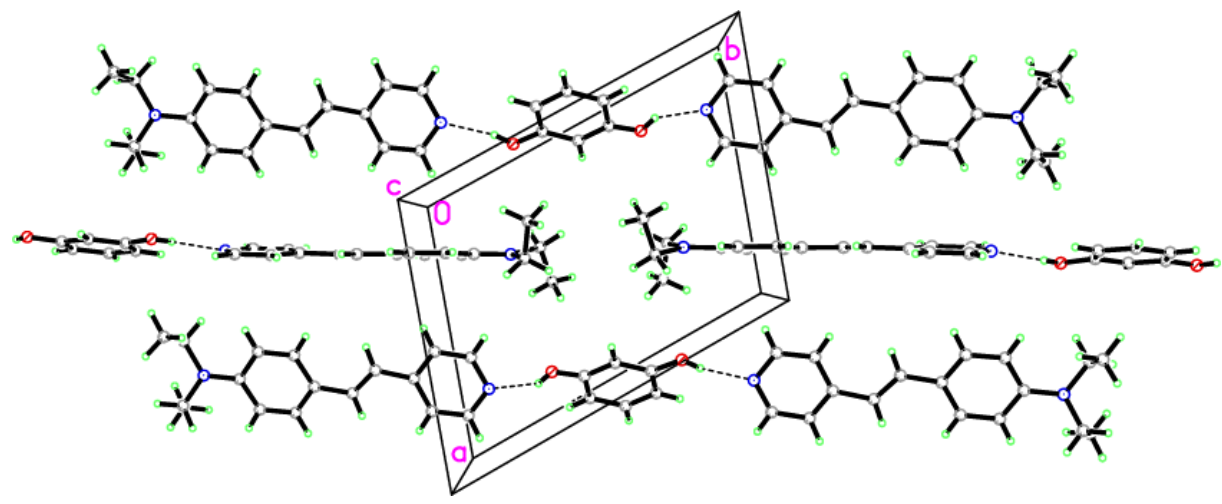

(b)

Fig. 6. (a) View of one of the trimeric units in 2(2) (III). (b) Fragment of crystal packing in 2(2)(III).

Adduct $3(\mathbf{3}) \cdot($ III $)$ with an unusual 3:1 molar ratio crystallizes in the non-centrosymmetric space group $P 1$. The triclinic unit cell comprises three crystallographically unique chromophore molecules $\mathbf{3}$, and one diol molecule III as it is shown in Fig. 7a. The two chromophore molecules $\mathbf{3}$ defined by the $\mathrm{N} 1 / \mathrm{N} 2 / \mathrm{N} 3 / \mathrm{N} 4$ and N5/N6/N7/N8 atoms are almost coplanar with the dihedral angle of $6.13(12)^{\circ}$ between their skeletons (excluding the terminal methyl groups). The third molecule $\mathbf{3}$ defined by the N9/N10/N11/N12 atoms is in a T-shape arrangement to both of them as the corresponding dihedral angles of 71.57(8) ${ }^{\circ}$ and 65.61(8) ${ }^{\circ}$ indicate. The deficiency of H-donors [5] in this cocrystal results in an exclusion of that last chromophore molecule $\mathbf{3}$ from the hydrogen-bonding system, and the most probably explains the crystallographic disorder of this molecule which obeys the pseudo center of symmetry. Two chromophore and one diol molecules form the acentric H-bonded adduct (Fig. 7b). Due to the metaposition of the pyridine nitrogen atom with respect to the azo-bridge in $\mathbf{3}$, the shape of the trimer differs substantially from the linear trimers $2(2) \cdot($ III). Here the bridging diol molecule III is located in a T-shape mode to both chromophore molecules 3, the corresponding dihedral angles being 71.75(7) and 73.40(7) ${ }^{\circ}$, thus forming the staircase-like entity. In the crystal the chromophores are packed in layers separated by the rows of diol molecules. Within the layer the H-bonded chromophores form the head-to-tail $\pi-\pi$ stacking dimers rather similar to the J-aggregates [38,39] with the 50\% molecule overlap and interplanar separations between the overlapping areas in the narrow range of 3.33-3.47 $\AA$. The dimers and the individual chromophore molecules alternate (Fig. 7c). 


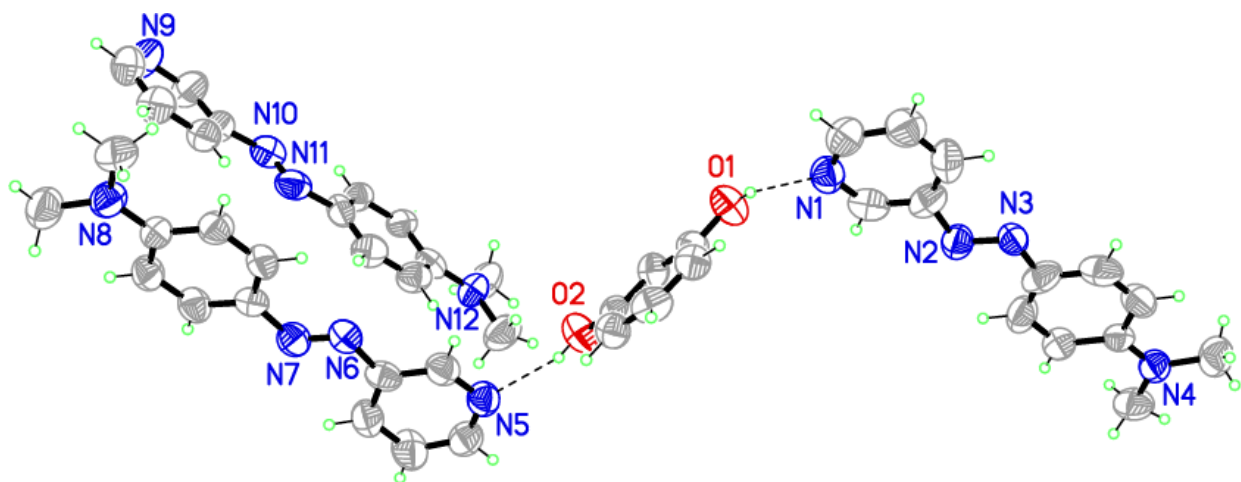

(a )

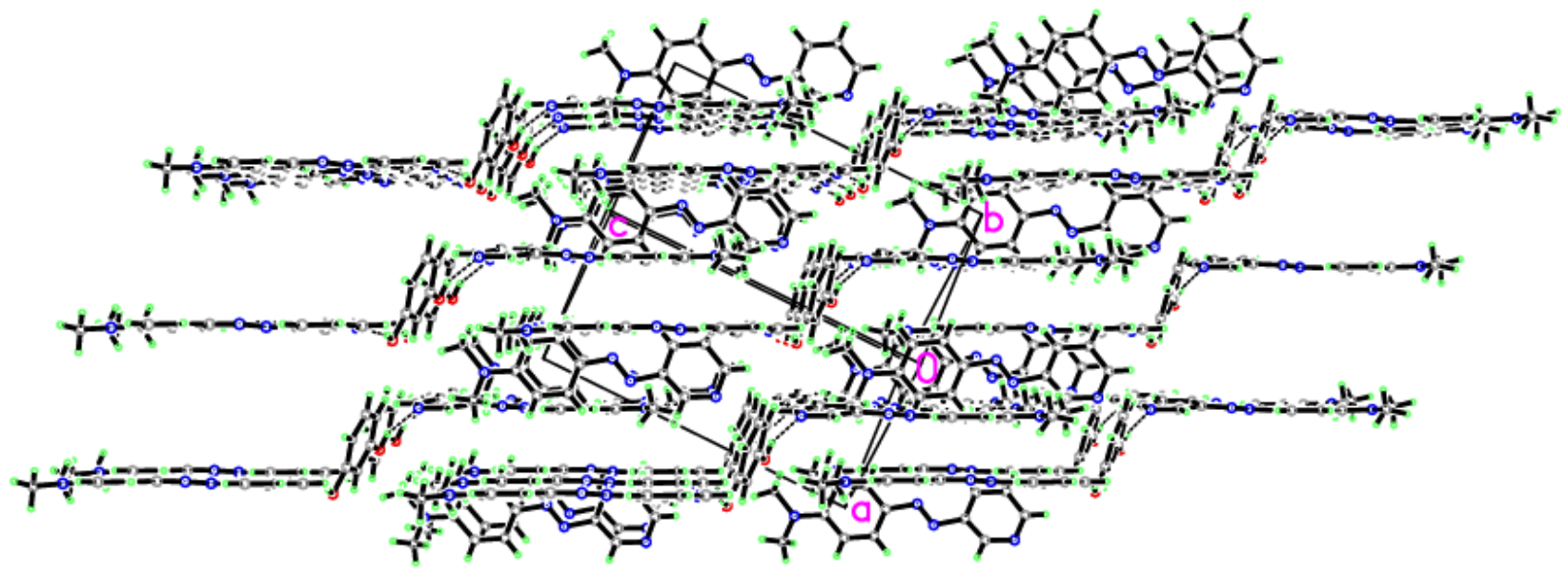

(b)

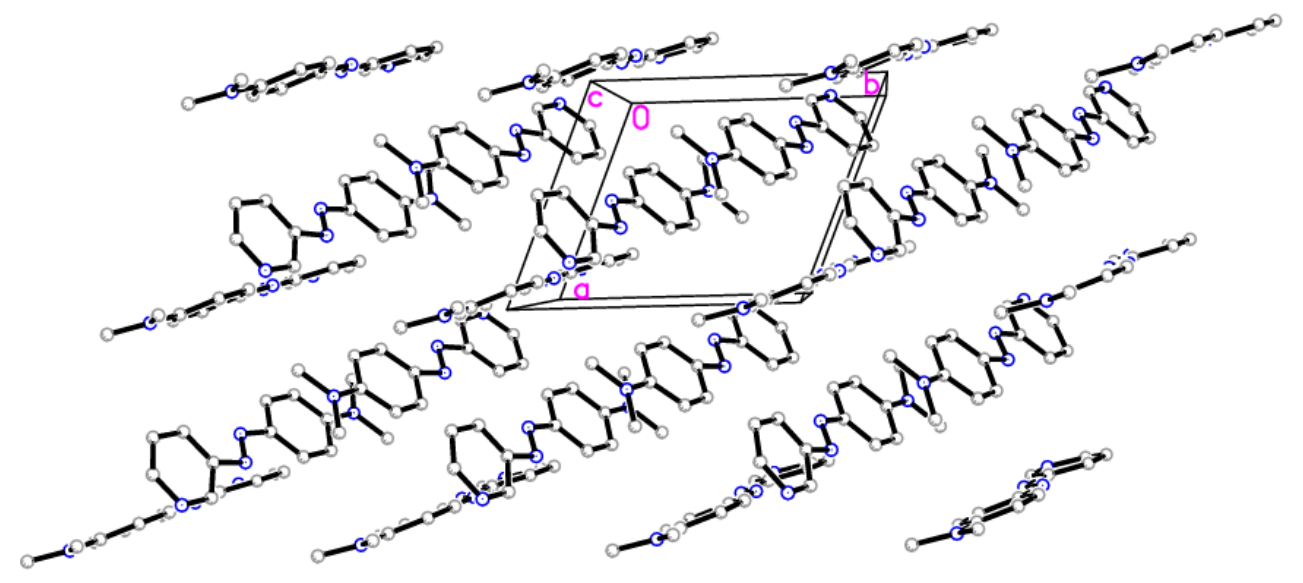

(c)

Fig. 7. (a) View of the formula unit in $3(3)$ (III). Thermal ellipsoids are drawn with the $50 \%$ probability level. Three-membered adduct sustained by $\mathrm{OH}^{\cdots}{ }^{\cdots} \mathrm{O}$ hydrogen bonds. (b) Crystal packing in 3(3) (III). (c) Fragment of layer of chromophores. H-atoms are omitted for clarity. 
Comparison of $2(\mathbf{2})^{\cdot}$ (III) and $3(\mathbf{3})^{\cdot}$ (III) shows that the altering position of pyridine nitrogen atom in chromophore 3 facilitates the acentric packing in the latter solid. On the other hand, the same chromophore $\mathbf{3}$ leads to the adduct with the phenol derivative IV crystallizing in a centric space group. The assessment of intermolecular interactions for identifying the most influential ones reveals the impact of the nitro-group adjacent to the phenolate group in coformer IV in the formation of $\mathrm{CH}^{\cdots *} \mathrm{O}$ hydrogen bond, as the impediment effect of intermolecular interactions on the NLO preferable crystal packing [22, 40]. These results suggest that the crystal packing of the reported adducts is very sensitive to the nature of the coformers.

Concluding this section, the speculations about the structure - melting point (MP) relationship might be done for adducts described herein. The inspection of Fig. 2 demonstrates the closeness of the MP of adduct to the MP of the starting refractory bases only for two of them, $\mathbf{1}$ (I) and $\mathbf{2}$ (II), whereas for the other systems that doesn't occur, and the MPs of the remaining adducts are essentially lower than for the bases. The reason for that could arise from the different hydrogen bonding systems. Only in $\mathbf{1}(\mathbf{I})$ and 2(II) the components are held together via the short practically linear single $\mathrm{NH}^{\cdots \cdots} \mathrm{O}$ hydrogen bond, while in the rest the hydrogen bonds are longer and twisted ones (Table 2). The similar trend has been recently reported by Kumar et al. for two isostructural Voriconazole cocrystals [41].

\subsection{Spectroscopic studies}

So far several attempts have been undertaken and reported to find correlations between the absorption spectra and NLO response for NLO active materials [40-42]. Coradin et al. [42] demonstrated that the active for the second harmonic generation (SHG) materials obtained by intercalation of cationic chromophore 4-[4-(dimethylamino)-R-styryl]-1-methylpyridinium iodide (DAMS+I-) into the layered $\mathrm{MPS}_{3}(\mathrm{M}=\mathrm{Cd}, \mathrm{Mn})$ matrices revealed the strong narrow band around $580 \mathrm{~nm}$ in the solid state UV-vis absorption spectra, assigned to the aggregation of chromophores in the J-type aggregates [38]. Contrary, other materials in spite of their large SHG efficiency, do not show the UV-vis absorption spectra typical for J-aggregates $[18,43]$. The explanation lies either in the masking of the J-band due to the additional intermolecular interactions that quench the expected J-type signal [44], or in the disruption of the ordered J-aggregates by dissolution in a polar organic solvent $[18,45]$. Although the solid state absorption and emission spectra for acentric solids allow to avoid some undesirable effects such as solvent polarity effect, the disaggregation and solvation processes, ionization of the components, and tautomeric transformations, the solution UV-Vis measurements are also reported specifically for the neutral compounds and tight ionic pairs as an effective useful tool to estimate the degree of aggregation of species in solution and to investigate the second-order NLO properties of aggregates by means of the Electric Field Induced Second Harmonic generation (EFISH) technique that can provide direct 
information on the intrinsic dipolar molecular second-order NLO properties, and can be extended to ionic species in case of a low polarity solvent which allows a significant ion-pairing [46, 47]. Keeping this in mind, the absorption spectra for four starting chromophores 1-4, and the acentric crystals $\mathbf{1}(\mathbf{I})$ and $3(3) \cdot($ III $)$ were measured at room temperature in a solvent of low electrical permittivity such as anhydrous chloroform [47], and shown in Fig. 8 together with the solvent emission spectra for $\mathbf{1}$ and $\mathbf{3}$.

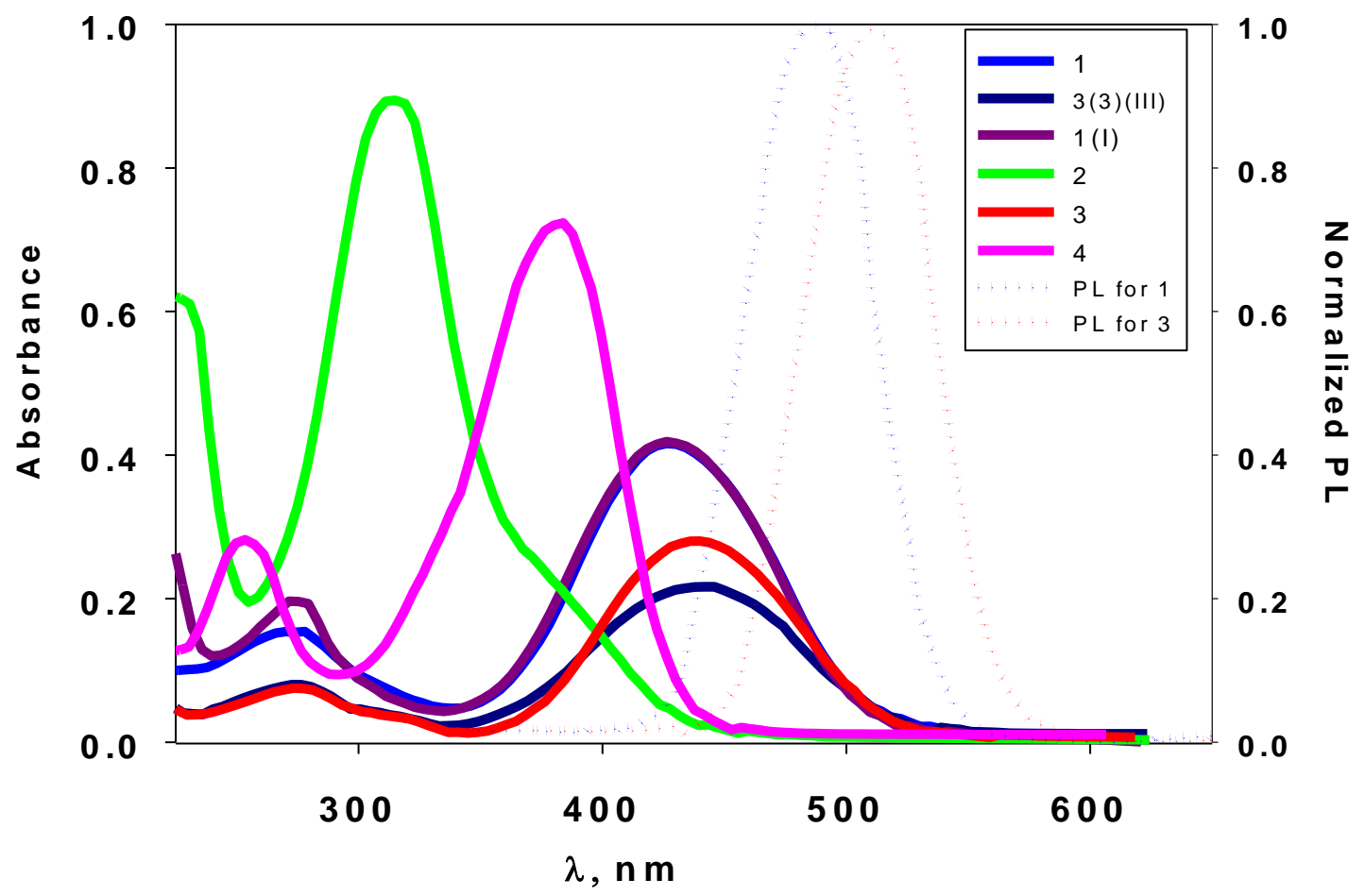

Fig. 8. Absorption and emission spectra for the selected reported compounds.

The absorption spectra exhibit the similar trends, revealing two absorption bands, one in the UV region between 220 and $280 \mathrm{~nm}$, and one - in the near visible region, from 300 till $450 \mathrm{~nm}$. In accordance with the literature [48] the latter band is attributed to the intramolecular $\pi-\pi^{*}$ transition, while the former and weaker one - to the feeble $\mathrm{n}-\pi^{*}$ transition being partially hidden by the strong $\pi-\pi^{*}$ band. The position of this band is strongly influenced by the structure of the compounds. The strong variation of the low energy band on going from chromophore 1 to 2 and from 3 to 4, that is with changing the alkyl amino groups from di-methyls to di-ethyls, is observed, and might be explained by the different impact of the different alkyl side-chains in the different modes of chromophores aggregations in the non-polar chloroform solvent. The impact of the alkyl-substituents in the aggregation patterns for different classes of dyes and in their spectroscopic characteristics is widely discussed nowadays [49-52]. All chromophores in this research show low cut off wavelength and therefore high transparency in the Vis-IR 
part of spectra, which is an important condition for phase matching in SHG process. The inspection of Fig. 8 reveals practically perfect overlapping of the absorption curves for starting bases $\mathbf{1}$ and $\mathbf{3}$ and their binary adducts thus indicating the preservation of the non-ionized species, and looking like the negligible sensitivity of the spectra to the second phenolic component, the observation being in line with the reported examples [18, 43, 53]. The only chromophores $\mathbf{1}$ and $\mathbf{3}$ with dimethyl functional group show meaningful emission with a pretty large Stokes' shifts of $65 \mathrm{meV}$ and $48 \mathrm{meV}$ respectively. The lack of the band around $580 \mathrm{~nm}$ responsible for the J-type aggregate registered in the crystal of $3(\mathbf{3}) \cdot(\mathbf{I I I})$ might be connected with the dissolution effects, and stimulates us for further investigation of the solid state absorption spectra for the new acentric compounds. The registered photoluminescence properties make the reported compounds useful for optoelectronic applications.

\section{Experimental}

\subsection{General}

All solvents were purchased from Aldrich and used without further purification. Melting points were determined on a Stanford research system (SRS) melting point apparatus and are uncorrected. Absorption and emission spectra were measured at room temperature in chloroform at $3 * 10^{-5} \mathrm{M}$ concentration. Absorption device: Hewlett-Packard 8452A spectrometer. Emission device: Perkin Elmer Luminescence Spectrometer LS50B.

The starting chromophores were recrystallized from : 1 from hot ethanol, yellow plate crystals, MP $245^{\circ} \mathrm{C}$, UV-Vis: $\lambda_{\max }=378 \mathrm{~nm}$; 2 : from hot methanol, red plate crystals, $M P 223^{\circ} \mathrm{C}, \lambda_{\max }=310 \mathrm{~nm}$; 3: from hot chloroform, red needle crystals, MP $231^{\circ} \mathrm{C}, \lambda_{\max }=440 \mathrm{~nm}$; : from hot chloroform, red plate crystals, MP $225^{\circ}$ C. $\lambda_{\max }=430 \mathrm{~nm}$.

\subsection{Synthesis}

3.2.1. Synthesis of 3. N,N-dimethyl-4-[(E)-pyridin-3-yldiazenyl]aniline $\mathbf{3}$ was synthesized according to the published procedure [12] and similar to the recently reported by us N,N-diethyl-4-[(E)-pyridin-3yldiazenyl]aniline 4 [32].

3.2.2. General procedure for the cocrystals preparation. All initial compounds are soluble in ethanol, acetone or chloroform, in dependence of the compound's individual solubility. In order to dissolve all amounts of chemicals, the solution was heated and sonicated for a couple of hours. For co-crystallization, initially the ratio of compounds was used as the ratio of donor to acceptor of compounds. The different ratio of coformers were used after that, but the stoichiometries of cocrystals were independent to the ratio of compounds used for the cocrystal growth. After mixing the desired amounts of chromophore and 
coformer the test tubes were covered with parafilm with some small holes in it. After a couple of days the solvent was evaporated and single crystals were obtained. All compounds obtained are stable at ambient conditions.

3.2.3. Synthesis of $\boldsymbol{I}(\boldsymbol{I})$ : 4-Nitrophenol $\mathbf{I}(1 \mathrm{mmol})$ was dissolved in hot ethanol $(150 \mathrm{~mL})$ set to sonication. Separately $N, N$-dimethyl-4-[(E)-2-(pyridin-4-yl)ethenyl]aniline 1 (1 mmol) was dissolved in ethanol $(100 \mathrm{~mL})$ and then mixed upon stirring with 4-nitrophenol solution. After slow evaporation platelike orange crystals were obtained, $\mathrm{MP}=245^{\circ} \mathrm{C}$.

3.2.4. Synthesis of $\mathbf{2}(\boldsymbol{I I})$ : 4-Nitrocarboxylic acid $\mathbf{I I}(1 \mathrm{mmol})$ was dissolved in of hot ethanol (150 mL) and set to sonication. Separately of $N, N$-diethyl-4-[(E)-2-(pyridin-4-yl)ethenyl]aniline (1 mmol) was dissolved in ethanol $(100 \mathrm{~mL})$ then combined with the 4-nitrocarboxylic acid solution. After slow evaporation plate-like red crystals were obtained, $\mathrm{MP}=220^{\circ} \mathrm{C}$.

3.2.5. Synthesis of 2(2)(III): 1,3-Benzenediol III (1 mmol) was dissolved in hot ethanol (150 mL) and set to sonication. Separately $N, N$-diethyl-4-[(E)-2-(pyridin-4-yl)ethenyl]aniline (2 mmol) was dissolved in ethanol $(100 \mathrm{~mL})$ and then combined with the 1,3-benzenediol solution. After slow evaporation blocklike red crystals were obtained, $\mathrm{MP}=190^{\circ} \mathrm{C}$.

3.2.6. Synthesis of 3(3)(III): 1,3-Benzenediol III (1 mmol) was dissolved in hot acetone (150 mL) and set to sonication. Separately of N,N-dimethyl-4-[(E)-pyridin-3-yldiazenyl]aniline (2 mmol) was dissolved in ethanol $(100 \mathrm{~mL})$ and then combined with the 1,3-benzenediol solution. After slow evaporation plate-like red crystals were obtained, $\mathrm{MP}=185^{\circ} \mathrm{C}$.

3.2.7. Synthesis of $\mathbf{3}(\boldsymbol{I V})$ : 2,4-Dinitrophenol IV (1 $\mathrm{mmol})$ was dissolved in hot chloroform (150 $\mathrm{mL})$ and set to sonication. Separately N,N-dimethyl-4-[(E)-pyridin-3-yldiazenyl]aniline (2mmol) was dissolved in ethanol $(100 \mathrm{~mL})$ and then combined with the 2,4-dinitrophenol solution. After slow evaporation platelike red crystals were obtained, $\mathrm{MP}=188^{\circ} \mathrm{C}$.

3.3. Single-Crystal X-ray Diffraction Analysis. Single crystal X-ray data for $\mathbf{1} \cdot(\mathbf{I}), \mathbf{2}(\mathbf{I I}), 2(\mathbf{2}) \cdot(\mathbf{I I I}), \mathbf{3}$ (IV), and $3(\mathbf{3}) \cdot($ III $)$ were collected on a Bruker-AXS SMART APEX CCD diffractometer with monochromatized Mo K $\alpha$ radiation $(\lambda=0.71073 \AA$ ). Data were collected at=100(2) K for $\mathbf{1}(\mathbf{I}), \mathbf{2} \cdot(\mathbf{I I}), \mathbf{3}$, and $3(\mathbf{3}) \cdot(\mathbf{I I I})$, and at $295(2) \mathrm{K}$ for $2(\mathbf{2}) \cdot($ III) and $3 \cdot(\mathbf{I V})$. Lattice parameters were determined from the least-squares analysis, and reflection data were integrated with the SAINT + program using narrow-frame algorithm [54]. Lorentz and polarization corrections were applied for diffracted reflections. Absorption corrections were applied using the semiempirical method of the SADABS program [55]. The structures were solved by direct methods and refined using the Bruker SHELXTL programs suite [56] by fullmatrix least-squares methods on $F^{2}$ with $S H E L X L-97$ in anisotropic approximation for all non-hydrogen atoms. The $\mathrm{O}-$ and $\mathrm{N}$-bound $\mathrm{H}$-atoms were located from the difference Fourier map and refined freely in $\mathbf{1} \cdot(\mathbf{I}), \mathbf{2} \cdot(\mathbf{I I})$, and $\mathbf{3} \cdot(\mathbf{I V})$, and fixed at the latest stages of refinement in $2(\mathbf{2}) \cdot(\mathbf{I I I})$ and $3(\mathbf{3}) \cdot(\mathbf{I I I})$, In $\mathbf{1} \cdot(\mathbf{I})$ the 
chromophore molecule 1 is disordered over two positions with the occupancies 0.599(3) and 0.401(3). In 2(2)(III) the hydroxy groups in two diol molecules III are disordered over two crystallographically identical positions with equal probabilities. The C-atoms of the stilbene bridges in two molecules 2 are disordered over two positions with the occupancies 709(9) and 0.291(9), and 0.894(4) and 0.106(4), respectively. In $\mathbf{3}(\mathbf{I V})$ the $\mathrm{N}, \mathrm{N}$-dimethylaminobenzene ring of the chromophore molecule $\mathbf{3}$ is disordered over two positions with equal probabilities. In $3(\mathbf{3}) \cdot($ III) one of the chromophore molecules 3 is disordered over two positions related by the pseudo-inversion center with the partial occupancies of 0.883(4) and 0.117(4), the minor component was refined in isotropic approximation, in one more molecule 3 the nitrogen atoms of the azo-bridge are disordered over two positions with the occupancies $0.71(1)$ and $0.39(1)$.

CCDC 1004553-1004558 contain the supplementary crystallographic data for all compounds. These data can be obtained free of charge from The Cambridge Crystallographic Data Centre via www.ccdc.cam.ac.uk/data request/cif.

\section{Conclusions}

Our search of organic solids for NLO applications resulted in five new binary adducts with stilbene and azobenzene-like chromophores that include alongside with the known N,N-dimethyl-4-[(E)-2-(pyridin-4yl)ethenyl]aniline) $\mathbf{1}, \quad$ and N,N-diethyl-4-[(E)-2-(pyridin-4-yl)ethenyl]aniline) 2 , also the newly synthesized N,N-dimethyl-4-[(E)-pyridin-3-yldiazenyl]aniline 3. In the case of N,N-dimethyl-4-[(E)pyridin-3-yldiazenyl]aniline the replacing of "diethyl" group with the "dimethyl" one changes the crystal packing from the acentric to the centrosymmetric one. As the coformers, 4-nitrophenol $\mathbf{I}$, and its derivatives and analogues, 4-nitrobenzoic acid II, benzene-1,3-diol III, and 2,4-dinitrophenol IV were used. Adducts differ by the components' ratio and positions of the acidic hydrogen atom, thus giving examples of new cocrystals and salt. The single crystal X-ray analysis reveals the acentric crystal packing for two cocrystals, $\mathbf{1} \cdot(\mathbf{I})$ and $3(\mathbf{3}) \cdot(\mathbf{I I I})$ that crystallize in the $P c a 2_{1}$ and $P 1$ space groups, and demonstrate the aggregation of chromophores in two different types of layers in the crystals. The advantage of N,Ndimethyl-4-[(E)-pyridin-3-yldiazenyl]aniline $\mathbf{3}$ with the meta-position of the pyridine nitrogen atom in the chromophore molecule as a new potential component of acentric materials has been proven by the formation of acentric solid $3(\mathbf{3}) \cdot($ III $)$. Both new acentric materials are subjected to further investigation of their NLO properties. These findings afford a good starting point to collect more data on adducts of polar molecules for further investigation of regularities required for formation of acentric materials.

Acknowledgement: We are grateful to NSF DMR-0934212 (PREM), EPSCOR IIA-130134 


\section{References:}

[1] J.A. Delaire, K. Nakatani, Chem. Rev. 100 (2000) 1817.

[2] W. Bartkowiak, Solvatochromism and Nonlinear Optical Properties of Donor-acceptor $\pi$ Conjugated Molecules In: Non-Linear Optical Properties of Matter Challenges and Advances in Computational Chemistry and Physics 1 (2006) 299.

[3] L.R. Dalton, A.W. Harper, R. Ghosn, W.H. Steier, M. Ziarj, Y. Shi, R.V. Mustacich, A.K.-Y. Jen, K.J. Shea, Chem. Mater. 7 (1995) 1060.

[4] A. Facchetti, E. Annoni, L. Beverina, M. Morone, P. Zhu, T.J. Marks, G.A. Pagani, Nature Materials 3 (2004) 910.

[5] M.C. Etter, J. Phys. Chem. 95 (1991) 4601.

[6] M.C. Etter, G.M. Frankenbach, D.A. Adsmond, In: Molecular Crystals and Liquid Crystals Incorporating Nonlinear Optics 187 (1990) 25.

[7] V.A. Russell, M.C. Etter, M.D. Ward, Chem. Mater. 6 (1994) 1206.

[8] V. Videnova-Adrabinska, M.C. Etter, M.D. Ward, Engineering Solid-State Materials. Strategies for Modeling and Packing Control of Molecular Assemblies into 3-D Networks Technical rept. 1 Jun 92-31 May 93, Accession Number : ADA265291 PDF Url : ADA265291.

[9] C.C. Evans, M. Bagieu-Beucher, R. Masse, J.-F. Nivoud, Chem. Mater. 10 (1998) 847.

[10] S.R. Marder, J.W. Perry, W.P. Schaefer, Science 245 (no. 4918) (1989) 626.

[11] S.R. Marder, J.W. Perry, C.P. Yakymyshyn, Chem. Mater. 6 (1994) 1137.

[12] F. Pan, M.S. Wong, C. Bosshard, P. Günter, Adv. Mat. 8 (1996) 592.

[13] S. Sohma, H. Takahashi, T. Taniuchi, H. Ito, Chem. Phys. 245 (1999) 359.

[14] T. Kaino, B. Cai, K. Takayama, Adv. Funct. Mater. 12 (2002) 599.

[15] T. Taniuchi, S. Okada, H. Nakanishi, J. Appl. Phys. 95 (2004) 5984.

[16] A. Schneider, M. Neis, M. Stillhart, B. Ruiz, R.U.A. Khan, P.J. Günter, Opt. Soc. Am. B 23 (2006) 1822.

[17] S. Brahadeeswaran, Y. Takahashi, M. Yoshimura, M. Tani, S. Okada, S. Nashima, Y. Mori, M. Hangyo, H. Ito, T. Sasaki, Cryst. Growth Des. 13 (2013) 415.

[18] J.-S. Kim, J.-H. Jeong, H. Yun, M. Jazbinsek, J. W. Kim, F. Rotermund, O.-P. Kwon, Cryst. Growth Des. 13 (2013) 5085.

[19] S. Draguta, M.S. Fonari, A.E. Masunov, J. Zazueta, S. Sullivan, M.Yu. Antipin, T.V. Timofeeva, CrystEngComm 15 (2013) 4700.

[20] M.J. Prakash, T.P. Radhakrishnan, Cryst. Growth Des. 5 (2005) 721. 
[21] G. Anandha Babu, R.P. Ramasamy, P. Ramasamy, Mat. Chem. Phys. 117 (2009) 326.

[22] S. Draguta, A.A. Yakovenko, M.S. Fonari, T.V. Timofeeva, Cryst. Growth Des. 14 (2014) 3423.

[23] M. Khan, V. Enkelmann, G. Brunklaus, Cryst. Growth Des. 9 (2009) 2354.

[24] J.M. Robertson, Proc. R. Soc. London A157 (1936) 79.

[25] T. Kagawa, R. Kawai, S. Kashino, M. Haisa, Acta Crystallogr. B32 (1976) 3171.

[26] L. Guru Prasad, V. Krishnakumar, R. Nagalakshmi, Physica B: Condensed Matter 405 (2010) 1652.

[27] J. Chandrasekaran, S. Balaprabhakaran, B. Babu, Optik 124 (2013) 4296.

[28] M. Pickering, R.W.H. Small, Acta Crystallogr. B38 (1982) 3161.

[29] T. Akutagawa, T. Uchimaru, K. Sakai, T. Hasegawa, T. Nakamura, J. Phys. Chem. B 107 (2003) 6248.

[30] V. Krishnakumar, R. Nagalakshmi, S. Manohar, M. Piasecki, I.V. Kityk, P. Bragiel, Physica B: Condensed Matter 405 (2010) 839.

[31] N. Peor, R. Sfez, S.Yitzchaik, J. Am. Chem. Soc. 130 (2008) 4158.

[32] S. Draguta, E. Leonova, M. Fokina, I. Denisyuk, T.V. Timofeeva, Acta Crystallogr. E69 (2013) 01280.

[33] L.R. MacGillivray, J.L. Reid, J.A. Ripmeester, J. Am. Chem. Soc. 122 (2000) 7817.

[34] W. Lin, W. Lin, G.K. Wong, T.J. Marks, J. Am. Chem. Soc. 118 (1996) 8034.

[35] F.H. Allen, Acta Crystallogr. B58 (2002) 380.

[36] A. Whitaker, J. Crystallogr. Spectrosc. Res. 22 (1992) 151.

[37] U. Siemeling, C. Bruhn, M. Meier, C. Schirrmacher, Z. Naturforsch., B: Chem. Sci. 63 (2008) 1395.

[38] D. Möbius, Adv. Mater. 7 (1995) 437.

[39] A. Mishra, R.K. Behera, P.K. Behera, B.K. Mishra, G.B. Behera, Chem. Rev. 100, (2000) 1973.

[40] J. M. Cole, T.-C. Lin, A. J. Edwards, R. O. Piltz, G. Depotter, K. Clays, S.-C. Lee, O-Pil Kwon, ACS Appl. Mater. Interfaces 7 (2015) 4693.

[41] S. S. Kumar, R. Thakuria, A. Nangia, CrystEngComm 16 (2014) 4722.

[42] T. Coradin, R. Clément, P. G. Lacroix, K. Nakatani, Chem. Mater. 8 (1996) 2153.

[43] F. Nunzi, S. Fantacci, E. Cariati, E. Tordin, N. Casati, P. Macchi, J. Mater. Chem. 20 (2010) 7652.

[44] F. Nunzi, S. Fantacci, F. De Angelis, A. Sgamellotti, E. Cariati, R. Ugo and P. Macchi, J. Phys. Chem. C, 2008, 112, 1213.

[45] E. Cariati, R. Macchi, D. Roberto, R. Ugo, S. Galli, N. Casati, P. Macchi, A. Sironi, L. Bogani, A. Caneschi, D. Gatteschi, J. Am. Chem. Soc. 129 (2007) 9410. 
[46] I. P. Oliveri, S. Failla, A. Colombo, C. Dragonetti, S. Righetto, S. Di Bella, Dalton Trans. 43 (2014) 2168.

[47] F. Tessore, E. Cariati, F. Cariati, D. Roberto, R. Ugo, P. Mussini, C. Zuccaccia, A. Macchioni, ChemPhysChem 11 (2010) 495.

[48] C. Toro, A. Thibert, L. De Boni, A.E. Masunov, F.E. Hernandez, J. Phys. Chem. B 112 (2008) 929.

[49] M. Kastler, W. Pisula, D. Wasserfallen, T. Pakula, K. Müllen, J. Am. Chem. Soc. 127 (2005) 4286.

[50] K. Balakrishnan, A. Datar, T. Naddo, J. Huang, R. Oitker, M. Yen, J. Zhao, L. Zang, J. Am. Chem. Soc. 128 (2006) 7390.

[51] P. Shen, Y. Liu, X. Huang, B. Zhao, N. Xiang, J. Fei, L. Liu, X. Wang, H. Huang, S. Tan, Dyes and Pigments 83 (2009) 187.

[52] S. M. Partington, A. D. Towns Dyes and Pigments 104 (2014) 123.

[53] B. Carlotti, G. Consiglio, F. Elisei, C. G. Fortuna, U. Mazzucato, A. Spalletti, J. Phys. Chem. A. 118 (2014) 3580 .

[54] SAINT+, Version 6.2a; Bruker Analytical X-ray System, Inc.: Madison, WI, 2001.

[55] SADABS, Bruker Analytical X-ray System, Inc.: Madison, WI, 1999.

[56] SHELXTL, Version 6.10; Bruker Analytical X-ray System, Inc.: Madison, WI, 1997. 
Table 1. Crystal data and structure refinement for $\mathbf{1} \cdot(\mathbf{I}), \mathbf{2}(\mathbf{I I}), 2(\mathbf{2})^{\circ}(\mathbf{I I I}), \mathbf{3}, 3(\mathbf{3})^{\circ}(\mathbf{I I I})$, and $\mathbf{3}(\mathbf{I V})$.

\begin{tabular}{|c|c|c|c|c|c|c|}
\hline $\begin{array}{l}\text { Identification } \\
\text { code }\end{array}$ & $\mathbf{1} \cdot(\mathrm{I})$ & $2 \cdot($ II $)$ & $2(2)^{\cdot}($ III $)$ & $\mathbf{3}$ & $3(3) \cdot($ III $)$ & $\mathbf{3}(\mathrm{IV})$ \\
\hline $\begin{array}{l}\text { Empirical } \\
\text { formula }\end{array}$ & $\mathrm{C}_{21} \mathrm{H}_{21} \mathrm{~N}_{3} \mathrm{O}_{3}$ & $\mathrm{C}_{24} \mathrm{H}_{25} \mathrm{~N}_{3} \mathrm{O}_{4}$ & $\mathrm{C}_{40} \mathrm{H}_{46} \mathrm{~N}_{4} \mathrm{O}_{2}$ & $\mathrm{C}_{13} \mathrm{H}_{14} \mathrm{~N}_{4}$ & $\mathrm{C}_{45} \mathrm{H}_{48} \mathrm{~N}_{12} \mathrm{O}_{2}$ & $\mathrm{C}_{19} \mathrm{H}_{18} \mathrm{~N}_{6} \mathrm{O}_{5}$ \\
\hline CCDC number & 1004553 & 1004554 & 1004555 & 1004556 & 1004557 & 1004558 \\
\hline Formula weight & 363.41 & 419.47 & 614.81 & 226.28 & 788.95 & 410.39 \\
\hline $\mathrm{T}, \mathrm{K}$ & $100(2)$ & $100(2)$ & $295(2)$ & $100(2)$ & $100(2)$ & $295(2)$ \\
\hline Crystal system & orthorhombic & triclinic & triclinic & monoclinic & triclinic & monoclinic \\
\hline Space group & $P c a 2_{1}$ & $P-1$ & $P-1$ & $P 2_{1} / c$ & $P 1$ & $P 2_{1} / n$ \\
\hline \multicolumn{7}{|l|}{$\begin{array}{l}\text { Unit cell } \\
\text { dimensions }\end{array}$} \\
\hline $\mathrm{a}, \AA$ & $42.972(9)$ & $6.8627(13)$ & $9.7312(12)$ & $6.1117(7)$ & 7.891(3) & $9.3446(8)$ \\
\hline $\mathrm{b}, \AA$ & $5.7074(12)$ & $7.4730(14)$ & $12.9689(16)$ & $18.072(2)$ & $9.535(4)$ & $5.1353(5)$ \\
\hline c, $\AA$ & $7.3489(15)$ & $21.628(4)$ & $15.0280(18)$ & $10.4656(12)$ & $14.954(6)$ & $39.335(4)$ \\
\hline$\alpha,^{\circ}$ & 90 & $96.395(4)$ & $100.313(2)$ & 90 & $90.502(8)$ & 90 \\
\hline$\beta,^{\circ}$ & 90 & $92.397(4)$ & $93.310(2)$ & $94.200(2)$ & $92.890(8)$ & $92.244(2)$ \\
\hline$\gamma,{ }^{\circ}$ & 90 & $111.652(4)$ & $108.330(2)$ & 90 & $112.108(8)$ & 90 \\
\hline $\mathrm{V}, \AA^{3}$ & $1802.4(6)$ & $1020.4(3)$ & $1758.0(4)$ & $1152.8(2)$ & $1040.6(7)$ & $1886.1(3)$ \\
\hline $\bar{Z}$ & 4 & 2 & 2 & 4 & 1 & 4 \\
\hline $\mathrm{D}$ (calcd) $\mathrm{Mg} / \mathrm{m}^{3}$ & 1.339 & 1.365 & 1.161 & 1.304 & 1.259 & 1.445 \\
\hline$\mu, \mathrm{mm}^{-1}$ & 0.091 & 0.094 & 0.072 & 0.082 & 0.081 & 0.108 \\
\hline $\mathrm{F}(000)$ & 768 & 444 & 660 & 480 & 418 & 856 \\
\hline $\begin{array}{l}\text { Reflections } \\
\text { collected }\end{array}$ & 32108 & 9890 & 16453 & 10645 & 10048 & 17218 \\
\hline $\begin{array}{l}\text { Independent } \\
\text { reflections }\end{array}$ & $\begin{array}{l}3512[\mathrm{R}(\mathrm{int})= \\
0.0437]\end{array}$ & $\begin{array}{l}4001[\mathrm{R} \text { (int) } \\
=0.0670]\end{array}$ & $\begin{array}{l}6534[\mathrm{R} \text { (int) } \\
=0.0421]\end{array}$ & $\begin{array}{l}2271[\mathrm{R} \text { (int) } \\
=0.0670]\end{array}$ & $\begin{array}{l}7824[\mathrm{R} \text { (int) } \\
=0.0244]\end{array}$ & $\begin{array}{l}3704[\mathrm{R} \text { (int) } \\
=0.0570]\end{array}$ \\
\hline $\begin{array}{l}\text { Data / restraints / } \\
\text { parameters }\end{array}$ & $\begin{array}{l}3512 / 73 / \\
310\end{array}$ & $\begin{array}{l}4001 / 0 / \\
287\end{array}$ & $\begin{array}{l}\text { 6534/ } 12 \\
/ 457\end{array}$ & $\begin{array}{l}2271 / 0 / \\
156\end{array}$ & $\begin{array}{l}7824 / 32 / \\
612\end{array}$ & $\begin{array}{l}3704 / 0 / \\
297\end{array}$ \\
\hline GOOF on $F^{2}$ & 1.125 & 0.958 & 1.003 & 1.063 & 0.981 & 1.014 \\
\hline $\begin{array}{l}\text { Final } R \text { indices } \\
{[I>2 \sigma(I)]} \\
R_{1}, w R_{2}\end{array}$ & $\begin{array}{l}0.0519 \\
0.1104\end{array}$ & $\begin{array}{l}0.0521 \\
0.1025\end{array}$ & $\begin{array}{l}0.0594 \\
0.1382\end{array}$ & $\begin{array}{l}0.0398 \\
0.1093\end{array}$ & $\begin{array}{l}0.0520 \\
0.0870\end{array}$ & $\begin{array}{l}0.0595 \\
0.1322\end{array}$ \\
\hline $\begin{array}{l}R \text { indices (all } \\
\text { data) } R_{1}, w R_{2}\end{array}$ & $\begin{array}{l}0.0561 \\
0.1130\end{array}$ & $\begin{array}{l}0.1193 \\
0.1318\end{array}$ & $\begin{array}{l}0.1607, \\
0.1873\end{array}$ & \begin{tabular}{|l|}
0.0424 \\
0.1119 \\
\end{tabular} & $\begin{array}{l}0.1441 \\
0.1207\end{array}$ & $\begin{array}{l}0.1149, \\
0.1620\end{array}$ \\
\hline $\begin{array}{l}\text { Largest diff. } \\
\text { peak and hole } \\
\mathrm{e} \AA^{-3}\end{array}$ & $\begin{array}{l}0.189 \text { and - } \\
0.192\end{array}$ & $\begin{array}{l}0.221 \text { and - } \\
0.264\end{array}$ & $\begin{array}{l}0.236 \text { and }- \\
0.283\end{array}$ & $\begin{array}{l}0.223 \text { and - } \\
0.270\end{array}$ & $\begin{array}{l}0.112 \text { and - } \\
0.153\end{array}$ & $\begin{array}{l}0.283 \text { and - } \\
0.260\end{array}$ \\
\hline
\end{tabular}


Table 2. Hydrogen bonds for $\mathbf{1}(\mathbf{I}), \mathbf{2}(\mathbf{I I}), 2(\mathbf{2}) \cdot($ III $), 3(\mathbf{3}) \cdot($ III $)$, and $\mathbf{3}(\mathbf{I V})\left[\AA\right.$ and $\left.^{\circ}\right]$.

\begin{tabular}{|c|c|c|c|c|c|}
\hline D-H...A & $\mathrm{d}(\mathrm{D}-\mathrm{H})$ & $\mathrm{d}\left(\mathrm{H}^{\cdots \cdots} \mathrm{A}\right)$ & $\mathrm{d}(\mathrm{D} \cdots \mathrm{A})$ & $\angle(\mathrm{DHA})$ & $\begin{array}{l}\text { Symmetry } \\
\text { transformation } \\
\text { for acceptor }\end{array}$ \\
\hline \multicolumn{6}{|l|}{$\mathbf{1}(\mathbf{I})$} \\
\hline $\mathrm{O}(1)-\mathrm{H}(1) \cdots \mathrm{N}(1)$ & $1.10(5)$ & $1.59(5)$ & $2.650(11)$ & $171(5)$ & $x, y, z$ \\
\hline \multicolumn{6}{|l|}{$2 \cdot($ II $)$} \\
\hline $\mathrm{O}(1)-\mathrm{H}(1 \mathrm{O} 1)^{\cdots \cdots} \mathrm{N}(2)$ & $1.14(4)$ & $1.42(4)$ & $2.557(3)$ & $178(3)$ & $x, y, z$ \\
\hline $\mathrm{C}(8)-\mathrm{H}(8) \cdots \mathrm{O}(2)$ & 0.93 & 2.50 & $3.138(4)$ & $126(2)$ & $x, y, z$ \\
\hline \multicolumn{6}{|l|}{$2(2) \cdot($ III $)$} \\
\hline $\mathrm{O}(1)-\mathrm{H}(1)^{\cdots} \mathrm{N}(1)$ & 0.82 & 1.98 & $2.752(5)$ & 157 & $x+1, y, z$ \\
\hline $\mathrm{O}(2)-\mathrm{H}(2) \cdots \mathrm{N}(1)$ & 0.82 & 2.02 & $2.798(5)$ & 158 & $x+1, y, z$ \\
\hline $\mathrm{O}(3)-\mathrm{H}(3) \cdots \mathrm{N}(3)$ & 0.82 & 2.05 & $2.784(5)$ & 149 & $x, y-1, z$ \\
\hline $\mathrm{O}(4)-\mathrm{H}(4) \cdots \mathrm{N}(3)$ & 0.82 & 1.97 & $2.738(5)$ & 155 & $x, y-1, z$ \\
\hline \multicolumn{6}{|l|}{$3(3)^{\circ}($ III $)$} \\
\hline $\mathrm{O}(2)-\mathrm{H}(2 \mathrm{O}){ }^{\cdots} \mathrm{N}(5)$ & 0.82 & 2.02 & $2.789(4)$ & 156 & $x+1, y, z$ \\
\hline $\mathrm{O}(1)-\mathrm{H}(1 \mathrm{O}){ }^{\cdots} \mathrm{N}(1)$ & 0.82 & 2.00 & $2.771(5)$ & 156 & $x-1, y, z-1$ \\
\hline \multicolumn{6}{|l|}{$3 \cdot($ IV $)$} \\
\hline $\mathrm{N}(3)-\mathrm{H}(3) \cdots \mathrm{O}(1)$ & $1.03(4)$ & $1.60(4)$ & $2.565(3)$ & $153(3)$ & $x, y, z$ \\
\hline $\mathrm{N}(3)-\mathrm{H}(3) \cdots \mathrm{O}(2)$ & $1.03(4)$ & $2.31(4)$ & $2.972(4)$ & 121(3) & $x, y, z$ \\
\hline $\mathrm{C}(11)-\mathrm{H}(11) \cdots \mathrm{O}(2)$ & 0.93 & 2.47 & $3.032(4)$ & $119(2)$ & $x, y, z$ \\
\hline
\end{tabular}

